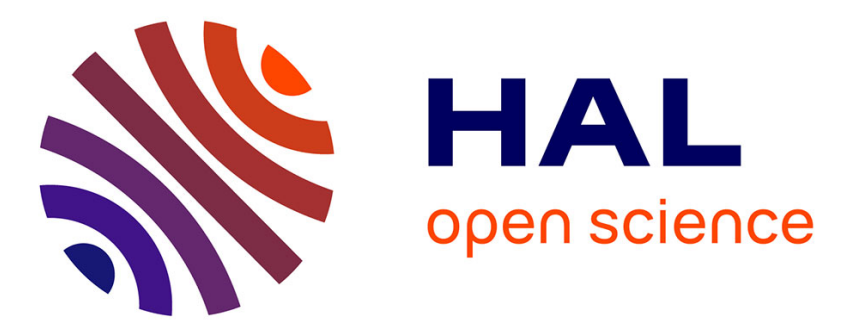

\title{
Do trace metals influence visual signals? Effects of trace metals on iridescent and melanic feather colouration in the feral pigeon
}

\author{
Marion Chatelain, Ana s Pessato, Adrien Frantz, Julien Gasparini, Sarah
} Leclaire

\section{To cite this version:}

Marion Chatelain, Ana s Pessato, Adrien Frantz, Julien Gasparini, Sarah Leclaire. Do trace metals influence visual signals? Effects of trace metals on iridescent and melanic feather colouration in the feral pigeon. Oikos, 2017, 126 (11), pp.1542-1553. 10.1111/oik.04262 . hal-01527274

\section{HAL Id: hal-01527274 https://hal.sorbonne-universite.fr/hal-01527274}

Submitted on 24 May 2017

HAL is a multi-disciplinary open access archive for the deposit and dissemination of scientific research documents, whether they are published or not. The documents may come from teaching and research institutions in France or abroad, or from public or private research centers.
L'archive ouverte pluridisciplinaire HAL, est destinée au dépôt et à la diffusion de documents scientifiques de niveau recherche, publiés ou non, émanant des établissements d'enseignement et de recherche français ou étrangers, des laboratoires publics ou privés. 
Do trace metals influence visual signals? Effects of trace metals on iridescent and melanic feather colouration in the feral pigeon

Chatelain $\mathrm{M}^{1 \dagger^{*}}$, Pessato $\mathrm{A}^{2 \dagger}$, Frantz $\mathrm{A}^{1}$, Gasparini $\mathrm{J}^{1}$ and Leclaire $\mathrm{S}^{2,3}$

${ }^{1}$ Sorbonne Universités, UPMC Univ Paris 06, UPEC, Paris 7, CNRS, INRA, IRD, Institut d'Ecologie et des Sciences de l'Environnement de Paris, F-75005, Paris, France

${ }^{2}$ Centre d'Ecologie Fonctionnelle et Evolutive, UMR 5175, CNRS, 1919 route de Mende, 34293 Montpellier, France

${ }^{3}$ Laboratoire Evolution \& Diversité Biologique, UMR 5174 (CNRS, Université Paul Sabatier, ENFA), 118 route de Narbonne, 31062 Toulouse, France

† First co-authors

${ }^{*}$ Corresponding author: Warsaw University, Center of New Technologies, S. Banacha 2c, 02097 Warsaw, Poland marion.chatelain@live.fr Orcid ID: 0000-0001-9168-5022 


\section{ABstract}

Trace metals are chemical pollutants of prime concern nowadays given their implication in several human diseases and their noxious effects on wildlife. Previous studies demonstrated their negative (e.g. lead, cadmium) or positive (e.g. zinc) effects on body condition, immunity and reproductive success in birds. Because of their effects on bird condition, trace metals are likely to influence the production of condition-dependent plumage colours, that may be used in mate choice. In the feral pigeon (Columba livia), we investigated iridescent colouration in response to lead and zinc experimental (i.e. metal supplementation in standardized conditions) and natural exposure (i.e. metal concentrations in feathers of wild urban pigeons), and melanic feather colouration in response to experimental lead and zinc exposure. Both studies (i.e. experimental and correlative) consistently showed that lead exposure decreased iridescent neck feather brightness independently of colour morph. Moreover, lead, when provided alone, decreased melanic feather reflectance in the middle wavelengths while zinc supplementation increased melanic feather reflectance in the violetwavelength. In conclusion, our study suggests that the colouration of iridescent and melanic feathers depends on the exposure to pollutants. Whether trace metal exposure affected the ability of birds to produce melanin pigments, to grow the microstructural feather elements required for maximum colour display, or to cope with bacteria that degrade feather microstuctures remains unclear. Future studies should investigate whether these metalinduced modifications of plumage colouration affect behaviours involved in sexual selection. 


\section{INTRODUCTION}

Integument colouration is arguably the most widespread visual display in animals (e.g. Hill and McGraw 2006). It can result from pigments (e.g. carotenoids, melanin) or from the structure of the underlying tissue (e.g. barbule density and barb cortex size in feathers). In numerous species, colourful ornaments are honest signals of individual quality, and are thus involved in various aspects of sexual selection (e.g. mate choice, male-male competition). For instance, carotenoid-based colouration is positively related to clutch size, recruitment probability, body size or immunocompetence, and is therefore used in mate choice and agonistic interactions in taxa as diverse as birds, reptiles or fish (Maan 2006, Doutrelant et al. 2007, Cote et al. 2010). The correlations between integument colouration and proxies of individual quality often result from the production or maintenance of these ornaments being condition-dependent: only individuals in good health (i.e. having the capacity to maintain optimal functionality of body systems) can afford the costs associated to colour production or maintenance (Zahavi and Zahavi 1997, Roulin 2016).

Trace metals (e.g. cadmium, lead, zinc, etc.) are mainly emitted by anthropogenic activities (Nriagu 1989, Bilos et al. 2001, Azimi et al. 2005), leading to elevated concentrations in urban areas compared to rural areas (Manta et al. 2002, Azimi et al. 2003, Roux and Marra 2007, Maas et al. 2010). Most of these elements are toxic (Hsu et al. 2006). For instance, lead exposure induces oxidative stress (Nuran Ercal et al. 2001, Valko et al. 2005, Berglund et al. 2007) and immunosuppression (Snoeijs et al. 2004, Chatelain et al. 2016a). On the contrary, some trace metals, such as zinc and copper, are essential elements (Powell 2000, Prasad 2009, Plum et al. 2010), though harmful effects can also occur at high concentrations. For instance, small quantities of zinc are often considered as beneficial to organisms (Prasad 1998), whereas high quantities can induce neurological problems (Greenberg and Briemberg 2004). By affecting body condition, trace metal exposure is therefore likely to affect condition-dependent plumage colouration. In the great tit (Parus 
major), carotenoid-based plumage colouration is negatively correlated with trace metal pollution (Dauwe and Eens 2008, Geens et al. 2009, Giraudeau et al. 2015) and with the size of the melanic breast-tripe (Dauwe and Eens 2008). Metal ions, including calcium, zinc and copper, are cofactors of tyrosinase, a crucial component of melanin synthesis, and may therefore affect melanin production (suggested in McGraw 2003, Niecke et al. 2003, Roulin 2016). However, the only evidence in birds is related to calcium exposure, which has been found to affect the size of the melanic breast-stripe in contrasting ways, with a positive effect in zebra finches (Taeniopygia guttata) (McGraw 2007), and a negative effect in house sparrows (Passer domesticus) (Stewart and Westneat 2010, 2013). Although trace metal pollution is a major environmental issue in urban habitats, the effect of metal pollution on plumage colouration, which is often used as a visual signal during social interactions, is poorly known. In particular, experimental studies investigating the direct effects of metals on bird plumage colouration are lacking.

Although the condition-dependence and production costs of carotenoid-based colouration has been largely documented during the past decade (Olson and Owens 1998, Grether 2000, Wong and Svensson 2011), relatively few studies have investigated such condition-dependence in structural and melanin-based colours (Fitzstephens and Getty 2000, Doucet 2002, McGraw et al. 2002, Hill et al. 2005, Kemp and Rutowski 2007, McGraw 2008, Roulin 2016). The condition-dependency of iridescent colours has long been ignored, but supportive evidence is growing (Fitzstephens and Getty 2000, Doucet 2002, McGraw et al. 2002, Hill et al. 2005, Kemp and Rutowski 2007). For instance, iridescent colouration of male damselflies (Calopteryx maculate) depends on their diet (Fitzstephens and Getty 2000), while parasite exposure suppresses the expression of structural plumage colouration in male wild turkeys (Meleagris gallopavo) (Hill et al. 2005). In contrast to carotenoid-based and iridescent colouration, melanin-based colouration has been suggested to be under tight genetic control (McGraw et al. 2002, Roulin 2004, Jacquin et al. 2013a) and to signal genetic quality (Roulin 2004). Recently, a review on the condition-dependence of melanin-based 
colouration highlighted only two experimental studies out of eleven that demonstrate an effect of bird condition (i.e. ectoparasitism and brood size) on melanic feather colouration (Roulin 2016). Nonetheless, three factors might particularly influence melanin-based colouration: testosterone levels, amino acid uptake and trace metal exposure (McGraw 2008). The influence of those environmental factors on melanin deposition are however still lacking support from experimental studies (McGraw 2008).

The feral pigeon (Columba livia) is an urban bird with high polymorphism in the intensity and pattern of melanin-based plumage colouration. Melanic colouration is thought to be used as a selection criterion during mate choice (reviewed in Johnston 1992, Johnston and Janiga 1995). Indeed, females preferentially mate with darker males (Burley 1977) and the number of heterotypic pairs is higher than expected under a random plumage colouration-based pairing (Johnston and Johnston 1989). Feral pigeons are darker in urban areas than in rural ones (Obukhova 2007, Jacquin et al. 2013b), and they produce darker fledglings when experimentally exposed to lead (Chatelain et al. 2016a). These results may stem either from selection for darker pigeons in polluted environments (Chatelain et al. 2014) or from condition-dependent melanogenesis. Pigeons also exhibit purple and green iridescent neck feathers. During agonistic and courtship behaviours, males inflate their crop, probably to increase the conspicuousness of iridescent feathers. Females have less iridescent feathers than males, and juveniles display no or low iridescence (Johnston 1992, Leclaire et al. 2014). Together, these observations suggest that iridescent neck feathers are likely to have evolved through sexual selection in pigeons. The condition-dependency of these iridescent ornaments has, however, yet to be determined.

To investigate whether trace metal exposure in urban areas affects pigeon iridescent and melanic plumage colouration, we chronically submitted pigeons to drinking and bath water supplemented with lead and/or zinc. Lead and zinc are two of the most abundant metals in urban areas (Azimi et al. 2003) and their exposure is expected to induce antagonistic effects. Because of the respective detrimental and beneficial effects of lead and 
zinc exposure on condition, we expected pigeons to exhibit lower feather colouration when exposed to lead and higher colouration when exposed to zinc. Through this experimental approach we tested whether birds from the different trace metal exposure treatments differ in iridescent and melanin-based colouration, independently of their colour morph. In addition, we verified the link between iridescent feather colouration and metal exposure in natural conditions through a correlative approach in wild pigeons inhabiting the Paris region.

\section{METHODS}

\section{Experimental approach}

\section{Subjects and Housing}

Free-living feral pigeons (Columba livia) were caught in February and March 2013 in several pigeons' flocks within Paris. A sample of 96 pigeons (48 males and 48 females genetically sexed) were chosen in such a way as to reflect the observed natural variation of melaninbased plumage colouration (Chatelain et al. 2014). At their capture, birds were first categorised as eumelanic (grey to black pigmented; 82 individuals: 37 males and 45 females) or pheomelanic (red pigmented; 14 individuals: 11 males and 3 females). Because the number of pheomelanic pigeons was small, all the analyses were performed on eumelanic birds only (but see table 1 in the supplementary material for a summary of plumage colouration in pheomelanic birds). Variation in the eumelanin-based colouration can be coded from 0 to 4 (Johnston and Janiga 1995): (0) for White (white mantle), (1) for Blue bar (grey mantle with two dark wing bars), (2) for Checker (checked mantle with moderate dark spots, (3) for T-pattern (dark mantle with small grey spots) and (4) for Spread (dark mantle; see picture 1 in the supplementary material). These four levels of eumelanin-based colouration are hereafter called the morph of the pigeon. Pigeons were kept in 8 outdoor aviaries $(2.20 \mathrm{~m} \times 2.20 \mathrm{~m})$ at the CEREEP field station (Centre d'Ecologie Expérimentale et 
Prédictive-Ecotron Ile-de-France, UMS 3194, Ecole Normale Supérieure, Saint-Pierre-lèsNemours, France). They were evenly distributed among aviaries according to their origin $\left(\mathrm{Chi}^{2}=71.09, \mathrm{df}=70, \mathrm{P}=0.441\right)$, sex (6 males and 6 females per aviary) and melanin-based plumage colouration $\left(\mathrm{Chi}^{2}=13.78, \mathrm{df}=28, \mathrm{P}=0.989\right)$. They were fed ad libitum with a mix of maize, wheat and peas. The aviaries were enriched with a bowl of water used for bathing and with branches as perches. Birds were individually identified with a numbered plastic ring. At the end of the experiment (i.e. after 9 months of captivity), birds were released back to the wild at their site of capture.

\section{Metal supplementation}

Before the start of the experiment, birds were acclimatized during a period ranging from 2 to 7 weeks, depending on their capture date, to reduce individual differences due to birds' previous exposure to metals and to remove potential stress effects of capture. There was no relation between acclimatization duration and aviary $\left(\mathrm{Chi}^{2}=65.27, \mathrm{df}=63, \mathrm{P}=0.398\right)$. Treatments consisted of tap water supplemented with either lead (Lead acetate, 1ppm; Sigma-Aldrich), zinc (Zinc sulphate, 10ppm; Prolabo), or zinc and lead (Lead acetate 1ppm and Zinc sulphate 10ppm), plus a control treatment (pure tap water). We chose these concentrations based on both lead blood concentrations measured in urban birds (ranging from 0,053 to 0,264ppm; Roux and Marra 2007) and the gastrointestinal absorption rate of lead in zebra finches calculated from Dauwe et al (2002) $(<10 \%)$. Zinc concentrations were approximated using zinc/lead concentrations ratio in the environment and bird feathers (Azimi et al. 2005, Frantz et al. 2012). In urban environments, birds are exposed to high concentrations of both lead and zinc (Azimi et al. 2003). Therefore, the simultaneous experimental exposure to lead and zinc is more representative of trace metal exposure in cities and allowed for testing for synergistic or antagonistic effects between these metals, which is expected from previous studies (Cerklewski and Forbes 1976, El-Gazzar et al. 1978). Each aviary was randomly assigned to one of the 4 treatments, resulting in 2 aviaries with 12 pigeons each per treatment (24 pigeons in total, including pheomelanic pigeons; 19, 
20, 24 and 19 eumelanic pigeons in the lead, the zinc, the lead+zinc and the control treatment, respectively). Water supplemented or not with zinc and/or lead was supplied ad libitum and replaced every other day both in drinking troughs and baths. The efficiency of our supplementation protocol to increase birds' exposure to lead and zinc was previously validated (Chatelain et al. 2016a). The treatments lasted 20 weeks.

\section{Iridescent and melanic feather reflectance measurement}

After 19 weeks of metal supplementation, 4 to 10 iridescent feathers were cut from the neck of each pigeon and stored in plastic bags until analysis. We measured the reflectance of the iridescent feathers with a reflectance spectrophotometer (Ocean Optics USB2000+), a deuterium-halogen light source (Ocean Optics DH2000 UV-Vis-NIR-lightsource) and a $200 \mu \mathrm{m}$ optical fiber reflectance probe. The probe was inserted in a black tube perpendicularly to the feather, without any contact between probe and feathers; reflectance was maximized by subsequently adjusting the angle. We slightly orientated the probe to maximize the reflectance. For each bird, we piled up 4 feathers to cover the background and eliminate its potential effect, and we took 3 different measures with different feathers and/or with different feather orders to quantify the patch of colour. We used SpectraSuite software 1.6.0-11 (Ocean Optics Inc) to measure reflectance in relation to a black background and a white standard (Spectralon, Labsphere). We calibrated the spectrophotometer every three samples. Pigeons display 2 kinds of iridescent neck feathers, the green and purple feathers, which show colour changes in opposite ways when reflection angles vary (McGraw 2004, Yin et al. 2006, Yoshioka et al. 2007). Reflectance of iridescent feathers was measured on both the feathers that appeared purple $(n=19)$ and the ones that appeared green $(n=56)$ to the human eye.

The reflectance of melanin-based colouration was measured on a regrown secondary remige $\left(\right.$ the $\left.5^{\text {th }}\right)$ removed after 12 weeks of treatments. For each eumelanic bird $(n=81$; one eumelanic bird died 7 weeks after the onset of the experiment), we took 3 measures at 3 different locations on the darker area of the feather. 


\section{Iridescent and melanic feather reflectance analysis}

To quantify pigeon colour variation as perceived by conspecifics, we used reflectance spectra and models developed for the tetrachromatic visual systems of birds to calculate brightness and the relative stimulation of pigeon photoreceptors (receptor quantum catches which correspond to the proportion of incident photons that are captured by the photopigment at each photoreceptor; Akutagawa and Ozaki 2012, Maia et al. 2013). In the tetrahedral colour model, a quantum catch for each photoreceptor type is calculated based on the photoreceptor sensitivities to wavelength $\lambda$, the reflectance spectrum of a coloured surface, the spectral distribution of incident light and the background reflectance to which the photoreceptors are assumed to have chromatically adapted (Vorobyev et al. 1998). We modeled spectral sensitivities of cone photoreceptors between 300 and $700 \mathrm{~nm}$ according to the model of Hart and Vorobyev (2005), using oil droplet and single cone photoreceptor spectral parameters of pigeons published by Bowmaker et al. (1997) and the ocular media transmittance of pigeons measured by Lind et al. (2013). We computed photoreceptor responses $\left(Q_{1}, Q_{2}, Q_{3}\right.$ and $Q_{4}$ quantum catches) and brightness using the Endler and Mielke's model (2005). We used the sum of the 2 longest-wavelength cones as the sensitivity data to calculate achromatic cone stimulation. We chose the standard illuminants D65 as a representative spectrum for open habitat midday ambient light. All spectral analyses were conducted with the "pavo" package (Maia et al. 2013) in R statistical software (R Development Core Team 2014). $Q_{1}$ was the photoreceptor response of the violet wavelengths-sensitive cone ( $\lambda_{\max }=404 \mathrm{~nm}$; the violet-sensitive receptor response), $\mathrm{Q}_{2}$ was the photoreceptor response of the short-wavelength sensitive cone $\left(\lambda_{\max }=452 \mathrm{~nm}\right.$; the bluesensitive receptor response), $Q_{3}$ was the photoreceptor response of the middle-wavelength sensitive cone $\left(\lambda_{\max }=506 \mathrm{~nm}\right.$; the green-sensitive receptor response) and $\mathrm{Q}_{4}$ was the photoreceptor response of the long-wavelength sensitive cone $\left(\lambda_{\max }=566 \mathrm{~nm}\right.$; the yellowsensitive receptor response; Hart and Vorobyev 2005). Repeatability (intraclass coefficient) between the three measures of reflectance per bird, calculated with the "ICC" package in R 
(Wolak et al. 2012), gave the following estimates (mean and (95\% confidence interval)): $Q_{1}$ 0.84 (0.78-0.89), $Q_{2} 0.64$ (0.53-0.73), $Q_{3} 0.57(0.45-0.68), Q_{4} 0.80$ (0.73-0.86) and brightness $0.52(0.40-0.64)$. Because metal exposure is unlikely to have an effect on the photoreceptor sensitivities, the spectral distribution of incident light or the background reflectance, we assume that quantum catches variations are linked to variations in the reflectance spectrum of the feather at the specific wavelengths. For this reason, we hereafter talk about the effects of trace metals on the reflectance in violet-wavelengths $\left(Q_{1}\right)$, blue wavelengths $\left(Q_{2}\right)$, greenwavelengths $\left(Q_{3}\right)$ and yellow-wavelengths $\left(Q_{4}\right)$.

\section{Feather melanic surface measurement}

The reflectance of melanin-based colouration was measured on a regrown secondary remige (the $5^{\text {th }}$ ) removed after 12 weeks of treatments. The removed feathers were individually photographed to precisely quantify feather melanic surface. Feather melanic surface was calculated as the percentage of black on the feather surface (number of black pixels/number of white pixels $x 100$ ) using the Gimp image retouching and editing software.

\section{Correlative approach}

While iridescent feather colouration may be influenced by experimental trace metal exposure in standardized conditions, it may depend on a combination of several environmental factors in the wild (e.g. food availability, exposure to parasites). Therefore, a correlative approach is useful to test the strength of trace metal effects on iridescent feather colouration in natural conditions. Thirty-one adult pigeons ( 21 females and 10 males genetically sexed) were caught in April and May 2013 in several pigeon flocks within the Parisian agglomeration. None of the 31 pigeons had pheomelanic pigmentation, and their melanin-based colour morph was coded as described above. Four to 10 iridescent feathers from the neck were cut at the base and stored in plastic bags until spectrophotometric analyses. We collected green iridescent feathers in 28 individuals and purple iridescent feathers in 3 individuals. Because 
of the low sample size of purple iridescent feathers, statistical analyses were performed on wild urban pigeons for which green feathers were collected (19 females and 9 males).

To monitor trace metal contamination, we measured lead and zinc concentrations in feathers, which are good estimates of pigeon exposure to these trace metals (Chatelain et al. 2016a). At capture, 2 feathers from the back, 2 feathers from the abdomen and 2 feathers from the wing were cut at the base and conserved in individual plastic bags. Metal quantitative analyses in feathers were performed following the method described in Chatelain et al. (2016a). Total lead and zinc concentrations were determined separately for each feather type (i.e. back, abdomen and wing) using mass spectrometry (quadrupole ICP-MS, XSerie II) and optical emission spectrometry (ICP-OES, JY 2000), respectively. Zinc levels and lead levels in the wing, abdomen and back feathers were all significantly correlated (zinc levels: all $r>0.40$, all $\mathrm{P}<0.02$; lead levels: all $r>0.44$, all $\mathrm{P}<0.02$ ). We therefore calculated the average lead and zinc levels in feathers for each individual, and carried out statistical analyses on these mean levels.

After measurement and sample collection, pigeons were transferred in outdoor aviaries at the CEREEP field station for the purpose of another study (Leclaire et al. 2015). At the end of the experiment (i.e. after 6 months of captivity), birds were released back to the wild at their site of capture. Here we focused on the measurements and samples collected at the day of capture.

\section{Statistical analyses}

All statistical analyses were performed using the R software (version 3.3.1).

For the experimental approach, we investigated the effects of trace metals on reflectance in violet, blue, green and yellow-wavelengths (i.e. quantum catches $Q_{1: 4}$ ), on brightness of both iridescent and melanic feathers, and on feather melanic surface, using linear models with lead exposure (binary coded: exposed or not), zinc exposure (binary coded: exposed or not), sex and their 2-way and 3-way interactions as explanatory variables. Plumage colour morph, and iridescent feather colour type (purple vs. green) and their 2-way 
interaction with sex were included as covariates to control for their expected effects on both iridescent and melanic feather colouration (this study, McGraw 2004, Yin et al. 2006, Yoshioka et al. 2007). For the correlative approach, we investigated the relation between trace metals and reflectance in violet, blue, green and yellow-wavelengths (i.e. quantum catches $Q_{1: 4}$ ) and brightness of iridescent feathers using linear mixed-effects models (computed using the Ime4 package) with mean lead levels (log-transformed), mean zinc levels (log-transformed), sex and their 2-way and 3-way interactions as explanatory variables. Plumage colour morph and its 2-way interaction with sex were included as covariates. Site of capture was included as a random factor.

For all linear models and linear mixed-effects models, we standardized predictor variables of the global model (i.e. with all the explanatory variables) using the "arm" package in R (Gelman et al. 2016) to be able to interpret the parameter estimates, especially of the interactions (Grueber et al. 2011). We used information theoretic methods - as model selection - in order to examine several hypotheses simultaneously and therefore to identify the best set of models based on the AIC (computed using the MuMIn package; Burnham and Anderson 2002, Grueber et al. 2011). Because we found several models with very close AIC $(\triangle \mathrm{AICc}<2)$, we rerun these top models using the restricted maximum likelihood approach (REML; for linear mixed-effects models only), and averaged with the natural average method (i.e. without shrinkage; Burnham and Anderson 2002, Grueber et al. 2011). We explored the effect of model parameters using the confidence interval (i.e. the range of values in which the population value may lie). Compared to null hypothesis testing, this approach is not influenced by extreme unobserved data, as the relative support in favor of the different hypotheses is assessed simultaneously. This approach, which allows simultaneous assessment of multiple hypotheses and takes model selection uncertainty into account, gives more robust parameter estimates (McCarthy 2007, Grueber et al. 2011). An explanatory variable was considered as having a significant effect on the response variable if its confidence interval did not include zero (Grueber et al. 2011). Relative importance (RI) was reported for each predictor. It corresponds to the sum of AIC weights over all submodels 
selected including the predictor (e.g. a RI of 1 means that the predictor was retained in all of the top models; Burnham and Anderson 2002, Symonds and Moussalli 2011).

Prior to model selection, colinearity between explanatory variables was assessed by calculating variance inflation factors (VIFs; Zuur et al. 2010). None of the variables had a VIF of $>2$ and they were thus all included in the model (Zuur et al. 2010).

\section{RESULTS}

\section{Experimental approach}

\section{Iridescent feathers reflectance}

Lead exposure had a significant effect on brightness (table 1a): birds not exposed to lead (i.e. control and zinc treatments) had higher brightness than birds exposed to lead (i.e. lead and lead+zinc treatments; table 1a; figure 1a). None of the predictors explained reflectance in violet-wavelengths (table 1a). Iridescent feather colour type (purple vs. green) had a significant effect on reflectance in blue, green and yellow-wavelengths (table 1a): reflectance in blue and yellow-wavelengths were lower in green feathers, while reflectance in greenwavelengths was higher in green feathers.

\section{Melanic feather reflectance}

Zinc exposure had a significant effect on reflectance in violet-wavelengths (table 2a): birds not exposed to zinc (i.e. control and lead treatments) had a lower reflectance in violetwavelengths than birds exposed to zinc (i.e. zinc and lead+zinc treatments; figure 3). The reflectance in green-wavelengths varied with the interaction between lead and zinc exposure and the interaction between morph and sex (table $2 \mathrm{a})$ : control birds had a higher reflectance in green-wavelengths than birds exposed to lead only (Student test: $t=-2.09, d f=34.58, C l=-$ $0.00347,-0.00005)$, whereas birds exposed to zinc (i.e. zinc or lead and zinc treatments) were in between (figure 3). Pale males (blue bar morph) had a higher reflectance in green- 
wavelengths than pale females (Student test: $t=-2.14, \mathrm{df}=26.93, \mathrm{Cl}=-0.00387,-0.00008$ ), while there was no difference between sexes in darker morphs. None of the predictors explained reflectance in blue and yellow-wavelengths or brightness (table 2a).

\section{Feather melanic surface}

Feather melanic surface significantly varied with zinc exposure and the interaction between morph and sex (table 2b). Melanic surface was in average $4 \%$ smaller in birds exposed to zinc (i.e. zinc and lead+zinc treatments; mean $\pm S E=0.300 \pm 0.012$ ) than in birds not exposed to zinc (i.e. control and lead treatments; mean $\pm S E=0.339 \pm 0.016$ ), and was positively correlated with colour morph in males (Estimate \pm adjusted SE $=0.060 \pm 0.015$, $\mathrm{Cl}=0.030,0.090)$ but not in females (Estimate \pm adjusted $\mathrm{SE}=0.037 \pm 0.020, \mathrm{Cl}=-0.002,0.076$ ).

\section{Correlative approach}

In Parisian pigeons naturally exposed to metals, iridescent-feather brightness was negatively correlated with lead levels (table $1 \mathrm{~b}$ and figure 1b). Reflectance in blue-wavelengths significantly varied with zinc levels and the interaction between zinc and lead levels (table 1b): reflectance in blue-wavelengths decreased with increasing lead levels in birds with low zinc levels, while reflectance in blue-wavelengths was not associated with lead levels in birds with high zinc levels (figure 2). Reflectance in violet-wavelengths and yellow-wavelengths significantly differed between males and females (table 1b): females had lower reflectance in violet-wavelengths, but higher reflectance in yellow-wavelengths, than males (mean (95\% Cl): $0.135(0.133,0.137)$ vs. $0.140(0.135,0.144)$, and $0.280(0.274,0.287)$ vs. 0.268 $(0.254,0.282)$, respectively). None of the predictors explained reflectance in greenwavelengths (table 1b).

\section{Discussion}


Lead is a toxic trace metal that can induce oxidative stress (Nuran Ercal et al. 2001, Valko et al. 2005, Koivula and Eeva 2010) and immunosuppression (Snoeijs et al. 2004, Gasparini et al. 2014, Chatelain et al. 2016a). In contrast, zinc is an essential nutrient which helps mounting immune responses for instance (Prasad 1998, 2009). Because iridescent colouration is known to be sensitive to stress (McGraw et al. 2002, Hill et al. 2005, Kemp et al. 2006), we expected lead and zinc exposure to affect iridescent feather colouration in feral pigeons. As predicted, pigeons exhibited lower iridescent feather brightness when experimentally or naturally (i.e. in the wild) exposed to lead. Interestingly, iridescent feathers of wild urban pigeons highly exposed to lead had low reflectance in blue-wavelengths $\left(\lambda_{\max }=\right.$ $452 \mathrm{~nm}$ ), except when simultaneously exposed to high levels of zinc, suggesting that zinc exposure may offset the effects of lead exposure. Accordingly, the negative effects of lead exposure on different proxies of individual quality (e.g. immunity, body condition at fledging) were not detected when zinc was provided in addition to lead in the feral pigeon (Chatelain et al. 2016a, b). Although iridescent feather colouration was not measured before trace metal supplementation, our experimental design, by equally distributing colour morphs among treatments is likely to have prevented any initial correlation between treatment and colouration. The causal effect of trace metal exposure on iridescent feather colouration is further supported by the pattern observed in the wild. Altogether, our results suggest that iridescent feather brightness may be an honest signal of metal-induced changes in condition in pigeons, which is consistent with the stress-induced effects demonstrated in other bird species and insects (Fitzstephens and Getty 2000, Doucet 2002, Kemp et al. 2006, Kemp and Rutowski 2007). In brown-headed cowbirds (Molothrus ater) for instance, males subjected to nutritional stress grow duller iridescent plumage than control males (McGraw et al. 2002), and in wild turkeys (Meleagris gallopavo), birds infected with coccidian parasites grow duller iridescent breast feathers than uninfected birds (Hill et al. 2005). Lead-induced stress may act similarly and therefore decrease the capacity of birds to grow bright iridescent feathers. Although the importance of neck feather colouration in pigeon signalling is 
unknown, several observations suggest that it may play a role in sexual selection. Males inflate their crop during agonistic and courtship behaviours, probably to increase the conspicuousness of iridescent feathers. Juveniles are less coloured than adults (Johnston 1992, Leclaire et al. 2014) and males and females exhibit dissimilar iridescent feather colourations (Johnston 1992, Leclaire et al. 2014). Although sex differences in iridescent colouration was found in natura, it was, however, not detected when pigeons were maintained in captivity, suggesting that sex differences in colouration result from different ecological niches between sexes (e.g. diet, habitat; Rose et al. 2006) or from differential effects of environmental conditions on colouration between sexes.

Unlike iridescent feather colouration, there is little evidence that melanic feather colouration might be influenced by stressful environmental conditions, with mixed results (McGraw et al. 2002, 2008, Roulin 2004, Jacquin et al. 2013a, Roulin 2016). Our study shows that lead, when provided alone, decreased the reflectance of melanic feathers in green-wavelengths $\left(\lambda_{\max }=506 \mathrm{~nm}\right)$, while zinc exposure increased the reflectance in violet-wavelengths $\left(\lambda_{\max }=404 \mathrm{~nm}\right)$. Moreover, melanic feather surface (i.e. the pigmented area of the feather) did not depend on lead exposure, but was lower in birds exposed to zinc. These results suggest that, in the feral pigeon, melanin-based colouration (as measured by reflectance spectrum and melanic surface) may partly depend on environmental parameters. Overall, melanin-based plumage colouration may signal pigeon genetic quality (Ducrest et al. 2008, Jacquin et al. 2011, 2013b, Roulin 2016), ability to store trace metals (Chatelain et al. 2014), ability to cope with feather-degrading bacteria (Goldstein et al. 2004, Gunderson et al. 2008) or condition (this study, McGraw 2008, Roulin 2016). In addition, the melanic feather reflectance difference between males and females suggests that it may have evolved under different selective pressures in both sexes. Further studies should investigate the role of eumelanic feather colouration in mate choice and its "indicator-value" by testing the link between such colouration and mate quality (e.g. investment in incubating, brooding or feeding). 
A key question concerns the proximate mechanism by which iridescent and melanic colouration can be condition-dependent. Changes in both colourations can arise from several non-exclusive mechanisms.

First, stress may affect the production or deposition of melanin pigments in growing feathers (suggested by McGraw et al. 2002, McGraw 2003, 2006, Griffith et al. 2006, Maia et al. 2011, Roulin 2016), by inducing the release of glucocorticoids, which are melanogenesis inhibitors (Slominski 2004, Roulin et al. 2008). In black-capped chickadees (Poecile atricapillus) and zebra finches however, stress does not decrease the production of melanin in feather barbs (D'alba 2014). Trace metals may also be directly involved on some steps of the melanogenesis pathway. In vitro studies demonstrated that zinc ions $\left(\mathrm{Zn}^{2+}\right)$ inhibit tyrosine hydroxylation, which is the rate-limiting step in melanogenesis (Jara et al. 1990, Furumura et al. 1998, Han et al. 2007). On the contrary, zinc concentrations in feathers increase with feather darkness (Niecke et al. 1999, Chatelain et al. 2014, 2016a), suggesting that zinc may be essential to produce melanin-based colouration by increasing melanogenesis (Niecke et al. 1999, McGraw 2003, 2006). In feral pigeons, while zinc exposure had no effect on feather darkness (i.e. brightness), it decreased melanic surface. This result suggests that the positive correlation between feather darkness and feather zinc concentration (Niecke et al. 1999, Chatelain et al. 2014, 2016a) may result from other mechanisms such as zinc linkage to melanin binding sites (Chatelain et al. 2014, 2016a). In addition, it suggests that the surface of the pigmented areas might not be under tight genetic control but might partly depend on environmental conditions including the exposure to some pollutants or the diet mineral content. Iridescent colour is produced by a heterostructure consisting of both keratin and melanosome nanostructures (e.g. laminar, crystal-like or quasiordered structure) in feather barbules (Eliason and Shawkey 2012, Xiao et al. 2014). Stress during feather growth may corrupt the production or arrangement of the microstructural feather elements, including melanosomes, required for maximum colour display (Maia et al. 
2011). In our study, because iridescent feathers were not plucked, we do not know, however, whether these feathers moulted during the experiment.

Second, stress may alter feather microstructure (DesRochers et al. 2009, D'Alba et al. 2014), which is known to contribute to variation in melanic colouration (Galván 2011, D'Alba et al. 2014). Variation in iridescent colouration may also result from changes in organisation, size and reflective index in the feather nanostructure. In pigeons, structural colours in iridescent neck feathers has been suggested to mostly originate from the interference in the top keratin cortex layer (Yin et al. 2006). The growth of feathers is a costly process (Brown 1985, Lindströem et al. 1993, Romero et al. 2005), and stress during moult may decrease the ability of birds to develop good-quality feathers (DesRochers et al. 2009, Lattin et al. 2011).

Third, feather microstructure may be altered by stress-induced changes in the load or composition of feather-degrading bacteria (Chatelain et al. 2015), meaning that the colour differences could be due to variation in the degree of depigmentation rather than on the degree of pigmentation (Roulin 2016). In pigeons, iridescent feather brightness increases with decreasing plumage bacterial load (Leclaire et al. 2014). Lead exposure, which modifies the composition and richness of plumage bacterial communities (Chatelain et al. 2015), might therefore affect feather colouration through its effect on bacterial communities in the feral pigeon. We may however, expect feather-degrading bacteria to differently affect feathers depending on their structure (e.g. thickness, barbule density, melanin concentration; Goldstein et al. 2004, Gunderson et al. 2008, Ruiz-De-CastañEda et al. 2012), which would consequently induce different effect magnitudes in melanic flight feathers, iridescent neck feathers or other feather types (e.g. down feathers). Alternatively, lead exposure may decrease feather brightness through its effect in decreasing the time spent preening (Chatelain et al. 2016). During preening, birds spread the waxy secretions of the preen gland onto their plumage, which are known to directly affect feather brightness (Piault et al. 2008, Delhey et al. 2008). However, because preen secretions decrease (rather than increase) feather and bill brightness in blue tits (Cyanistes caeruleus), mallards (Anas platyrhynchos) and tawny owls (Strix aluco) (Piault et al. 2008, Delhey et al. 2008), it is unlikely that the 
decreased feather brightness in pigeons with high lead levels (Chatelain et al. 2015) is due to their low preening frequency.

Here we showed that the exposure to lead and zinc, two of the most abundant metals in cities, affect both iridescent and eumelanic feather colouration of the feral pigeon. To understand the underlying mechanism that links trace metals to iridescent and melanic feather colouration, further studies should investigate the effects of metal exposure on both the concentration of melanin in feathers and the feather microstructure. While the role of these two colourations on social interactions remains unclear, trace metals are likely to modulate colour signals that might be used in sexual selection. Moreover, behavioural observations should be conducted to better understand the ecological significance of plumage colouration variation in this species and to what extent trace metal exposure in cities affects the reliability of plumage colour signals.

\section{REFERENCES}

Akutagawa, E. and Ozaki, K. 2012. Photoreceptors physiology, types, and abnormalities. Nova Science Publishers.

Azimi, S. et al. 2003. Trace metal determination in total atmospheric deposition in rural and urban areas. - Sci. Total Environ. 308: 247-256.

Azimi, S. et al. 2005. Sources, distribution and variability of hydrocarbons and metals in atmospheric deposition in an urban area (Paris, France). - Sci. Total Environ. 337: $223-239$ 
Berglund, A. et al. 2007. Oxidative stress in pied flycatcher (Ficedula hypoleuca) nestlings from metal contaminated environments in northern Sweden. - Environ. Res. 105: 330-339.

Bilos, C. et al. 2001. Sources, distribution and variability of airborne trace metals in La Plata City area, Argentina. - Environ. Pollut. 111: 149-158.

Bowmaker, J. K. et al. 1997. Visual pigments and oil droplets from six classes of photoreceptor in the retinas of birds. - Vision Res. 37: 2183-2194.

Brown, C. R. 1985. Energetic cost of moult in macaroni penguins (Eudyptes chrysolophus) and rockhopper penguins (E. chrysocome). - J. Comp. Physiol. B 155: 515-520.

Burley, N. 1977. Parental investment, mate choice, and mate quality. - Proc. Natl. Acad. Sci. U. S. A. $74: 3476-3479$.

Burnham, K. P. and Anderson, D. R. 2002. Information and likelihood theory: a basis for model selection and inference. - In: Burnham, K. P. and Anderson, D. R. (eds), Model Selection and Multimodel Inference. Springer New York, pp. 49-97.

Cerklewski, F. L. and Forbes, R. M. 1976. Influence of dietary zinc on lead toxicity in the rat. J. Nutr. 106: 689-696.

Chatelain, M. et al. 2014. The adaptive function of melanin-based plumage coloration to trace metals. - Biol. Lett. 10: 20140164-20140164.

Chatelain, M. et al. 2015. Experimental exposure to trace metals affects plumage bacterial community in the feral pigeon. - J. Avian Biol. 47: 521-529.

Chatelain, M. et al. 2016a. Do trace metals select for darker birds in urban areas? An experimental exposure to lead and zinc. - Glob. Change Biol. 22: 2380-2391. 
Chatelain, M. et al. 2016b. Trace metals, melanin-based pigmentation and their interaction influence immune parameters in feral pigeons (Columba livia). - Ecotoxicology in press.

Cote, J. et al. 2010. Carotenoid-based coloration, oxidative stress and corticosterone in common lizards. - J. Exp. Biol. 213: 2116-2124.

D'Alba, L. et al. 2014. Melanin-based color of plumage: role of condition and of feathers' microstructure. - Integr. Comp. Biol. 54: 633-644.

Dauwe, T. and Eens, M. 2008. Melanin- and carotenoid-dependent signals of great tits (Parus major) relate differently to metal pollution. - Naturwissenschaften 95: 969-973.

Dauwe, T. et al. 2002. Tissue levels of lead in experimentally exposed zebra finches (Taeniopygia guttata) with particular attention on the use of feathers as biomonitors. Arch. Environ. Contam. Toxicol. 42: 88-92.

Delhey, K. et al. 2008. Optical properties of the uropygial gland secretion: no evidence for UV cosmetics in birds. - Naturwissenschaften 95: 939-946.

DesRochers, D. W. et al. 2009. Exogenous and endogenous corticosterone alter feather quality. - Comp. Biochem. Physiol. A. Mol. Integr. Physiol. 152: 46-52.

Doucet, S. M. 2002. Structural plumage coloration, male body size, and condition in the blueblack grassquit. - The Condor 104: 30.

Doutrelant, C. et al. 2007. Female coloration indicates female reproductive capacity in blue tits. - J. Evol. Biol. 21: 226-233.

Ducrest, A. et al. 2008. Pleiotropy in the melanocortin system, coloration and behavioural syndromes. - Trends Ecol. Evol. 23: 502-510. 
El-Gazzar, R. M. et al. 1978. Influence of dietary zinc on lead toxicity in rats. - Toxicol. Lett. 1: 227-234.

Eliason, C. M. and Shawkey, M. D. 2012. A photonic heterostructure produces diverse iridescent colours in duck wing patches. - J. R. Soc. Interface 9: 2279-2289.

Endler, J. A. and Mielke, P. W. 2005. Comparing entire colour patterns as birds see them: colour pattern differences. - Biol. J. Linn. Soc. 86: 405-431.

Fitzstephens, D. M. and Getty, T. 2000. Colour, fat and social status in male damselflies, Calopteryx maculata. - Anim. Behav. 60: 851-855.

Frantz, A. et al. 2012. Contrasting levels of heavy metals in the feathers of urban pigeons from close habitats suggest limited movements at a restricted scale. - Environ. Pollut. 168: 23-28.

Furumura, M. et al. 1998. Metal ligand-binding specificities of the tyrosinase-related proteins. - Biochem. Biophys. Res. Commun. 242: 579-585.

Galván, I. 2011. Feather microstructure predicts size and colour intensity of a melanin-based plumage signal. - J. Avian Biol. 42: 473-479.

Gasparini, J. et al. 2014. Relationships between metals exposure and epidemiological parameters of two pathogens in urban pigeons. - Bull. Environ. Contam. Toxicol. 92: 208-212.

Geens, A. et al. 2009. Does anthropogenic metal pollution affect carotenoid colouration, antioxidative capacity and physiological condition of great tits (Parus major)? - Comp. Biochem. Physiol. Part C Toxicol. Pharmacol. 150: 155-163.

Giraudeau, M. et al. 2015. Metal exposure influences the melanin and carotenoid-based colorations in great tits. - Sci. Total Environ. 532: 512-516. 
Goldstein, G. et al. 2004. Bacterial degradation of black and white feathers. - The Auk 121: 656.

Greenberg, S. A. and Briemberg, H. R. 2004. A neurological and hematological syndrome associated with zinc excess and copper deficiency. - J. Neurol. 251: 111-114.

Grether, G. F. 2000. Carotenoid limitation and mate preference evolution: A test of the indicator hypothesis in guppies (Poecilia reticulata). - Evolution 54: 1712.

Griffith, S. C. et al. 2006. Melanin- versus carotenoid-based sexual signals: Is the difference really so black and red? - Anim. Behav. 71: 749-763.

Grueber, C. E. et al. 2011. Multimodel inference in ecology and evolution: challenges and solutions: Multimodel inference. - J. Evol. Biol. 24: 699-711.

Gunderson, A. R. et al. 2008. Resistance of melanized feathers to bacterial degradation: is it really so black and white? - J. Avian Biol. 39: 539-545.

Han, H.-Y. et al. 2007. The inhibition kinetics and thermodynamic changes of tyrosinase via the zinc ion. - Biochim. Biophys. Acta BBA - Proteins Proteomics 1774: 822-827.

Hart, N. S. and Vorobyev, M. 2005. Modelling oil droplet absorption spectra and spectral sensitivities of bird cone photoreceptors. - J. Comp. Physiol. A 191: 381-392.

Hill, G. E. and McGraw, K. J. 2006. Bird coloration. - Harvard University Press.

Hill, G. E. et al. 2005. The effect of coccidial infection on iridescent plumage coloration in wild turkeys. - Anim. Behav. 69: 387-394.

Hsu, M. J. et al. 2006. Taiwan's industrial heavy metal pollution threatens terrestrial biota. Environ. Pollut. 143: 327-334. 
Jacquin, L. et al. 2011. Melanin-based coloration is related to parasite intensity and cellular immune response in an urban free living bird: the feral pigeon Columba livia. - J. Avian Biol. 42: 11-15.

Jacquin, L. et al. 2013a. Darker female pigeons transmit more specific antibodies to their eggs than do paler ones. - Biol. J. Linn. Soc. 108: 647-657.

Jacquin, L. et al. 2013b. A potential role for parasites in the maintenance of color polymorphism in urban birds. - Oecologia 173: 1089-1099.

Jara, J. R. et al. 1990. Regulation of mammalian melanogenesis II: the role of metal cations. - Biochim. Biophys. Acta BBA - Gen. Subj. 1035: 276-285.

Johnston, R. F. and Johnson, S. G. 1989. Nonrandom Mating in Feral Pigeons. - The Condor 91: 23-29.

Johnston, R. F.. 1992. Rock dove: Columba livia.- American Ornithologists' Union.

Johnston, R. and Janiga, M. 1995. Feral pigeons. - Oxford University Press.

Kemp, D. J. and Rutowski, R. L. 2007. Condition dependence, quantitative genetics, and the potential signal content of iridescent ultraviolet butterfly coloration. - Evolution 61 : $168-183$.

Kemp, D. J. et al. 2006. Stress-mediated covariance between nano-structural architecture and ultraviolet butterfly coloration. - Funct. Ecol. 20: 282-289.

Koivula, M. J. and Eeva, T. 2010. Metal-related oxidative stress in birds. - Environ. Pollut. 158: 2359-2370.

Lattin, C. R. et al. 2011. Elevated corticosterone in feathers correlates with corticosteroneinduced decreased feather quality: a validation study. - J. Avian Biol. 42: 247-252. 
Leclaire, S. et al. 2014. Feather bacterial load affects plumage condition, iridescent color, and investment in preening in pigeons. - Behav. Ecol. 25: 1192-1198.

Leclaire, S. et al. 2015. Feather bacterial load shapes the trade-off between preening and immunity in pigeons. - BMC Evol. Biol. 15: 60.

Lind, O. et al. 2013. Ultraviolet vision in birds: the importance of transparent eye media. Proc. R. Soc. B Biol. Sci. 281: 20132209-20132209.

Lindströem, A. et al. 1993. The energetic cost of feather synthesis is proportional to basal metabolic rate. - Physiol. Zool.: 490-510.

Maan, M. E. 2006. Fitness correlates of male coloration in a Lake Victoria cichlid fish. Behav. Ecol. 17: 691-699.

Maas, S. et al. 2010. Spatial distribution of heavy metal concentrations in urban, suburban and agricultural soils in a Mediterranean city of Algeria. - Environ. Pollut. 158: 22942301.

Maia, R. et al. 2011. Nanostructural self-assembly of iridescent feather barbules through depletion attraction of melanosomes during keratinization. - J. R. Soc. Interface 9: 734-743.

Maia, R. et al. 2013. pavo : an $\mathrm{R}$ package for the analysis, visualization and organization of spectral data (A Tatem, Ed.). - Methods Ecol. Evol. 4: 906-913.

Manta, D. S. et al. 2002. Heavy metals in urban soils: a case study from the city of Palermo (Sicily), Italy. - Sci. Total Environ. 300: 229-243.

McCarthy, M. A. 2007. Bayesian methods for ecology. - Cambridge University Press.

McGraw, K. J. 2003. Melanins, metals, and mate quality. - Oikos: 402-406. 
McGraw, K. J. 2004. Multiple UV reflectance peaks in the iridescent neck feathers of pigeons. - Naturwissenschaften 91: 125-129.

McGraw, K. J. 2007. Dietary mineral content influences the expression of melanin-based ornamental coloration. - Behav. Ecol. 18: 137-142.

McGraw, K. J. 2008. An update on the honesty of melanin-based color signals in birds: New insights into melanin plumage. - Pigment Cell Melanoma Res. 21: 133-138.

McGraw, K. J. et al. 2002. Different colors reveal different information: How nutritional stress affects the expression of melanin-and structurally based ornamental plumage. - J. Exp. Biol. 205: 3747-3755.

Niecke, M. et al. 1999. Correlations between melanin pigmentation and element concentration in feathers of white-tailed eagles (Haliaeetus albicilla). - J. Für Ornithol. 140: 355-362.

Niecke, M. et al. 2003. Why do melanin ornaments signal individual quality? Insights from metal element analysis of barn owl feathers. - Oecologia 137: 153-158.

Nriagu, J. O. 1989. A global assessment of natural sources of atmospheric trace metals. Nature 338: 47-49.

Nuran Ercal, B. S. P. et al. 2001. Toxic metals and oxidative stress part I: Mechanisms involved in metal induced oxidative damage. - Curr. Top. Med. Chem. 1: 529-539.

Obukhova, N. 2007. Polymorphism and phene geography of the blue rock pigeon in Europe. - Russ J Genet 43: 492-501.

Olson, V. A. and Owens, I. P. F. 1998. Costly sexual signals: A carotenoids rare, risky or required? - Trends Ecol. Evol. 13: 510-514. 
Piault, R. et al. 2008. Experimental support for the makeup hypothesis in nestling tawny owls (Strix aluco). - Behav. Ecol. 19: 703-709.

Plum, L. M. et al. 2010. The essential toxin: Impact of zinc on human health. - Int. J. Environ. Res. Public. Health 7: 1342-1365.

Powell, S. R. 2000. The antioxidant properties of zinc. - J. Nutr. 130: 1447S-1454S.

Prasad, A. S. 1998. Zinc and immunity. - Mol. Cell. Biochem. 188: 63-69.

Prasad, A. S. 2009. Zinc: role in immunity, oxidative stress and chronic inflammation: - Curr. Opin. Clin. Nutr. Metab. Care 12: 646-652.

Romero, L. M. et al. 2005. Corticosterone inhibits feather growth: Potential mechanism explaining seasonal down regulation of corticosterone during molt. - Comp. Biochem. Physiol. A. Mol. Integr. Physiol. 142: 65-73.

Rose, E. et al. 2006. Spatio-temporal use of the urban habitat by feral pigeons (Columba livia). - Behav. Ecol. Sociobiol. 60: 242-254.

Roulin, A. 2004. The evolution, maintenance and adaptive function of genetic colour polymorphism in birds. - Biol. Rev. 79: 815-848.

Roulin, A. et al. 2008. Corticosterone mediates the condition-dependent component of melanin-based coloration. - Anim. Behav. 75: 1351-1358.

Roulin, A. 2016. Condition-dependence, pleiotropy and the handicap principle of sexual selection in melanin-based colouration: Melanin and sexual selection. - Biol. Rev. 91: 328-348.

Roux, K. E. and Marra, P. P. 2007. The presence and impact of environmental lead in passerine birds along an urban to rural land use gradient. - Arch. Environ. Contam. Toxicol. 53: 261-268. 
Ruiz-De-CastañEda, R. et al. 2012. Bacterial degradability of an intrafeather unmelanized ornament: a role for feather-degrading bacteria in sexual selection?: Bacteria, feather patch and sexual selection. - Biol. J. Linn. Soc. 105: 409-419.

Slominski, A. 2004. Melanin pigmentation in mammalian skin and its hormonal regulation. Physiol. Rev. 84: 1155-1228.

Snoeijs, T. et al. 2004. Heavy metal exposure affects the humoral immune response in a free-living small songbird, the great tit (Parus major). - Arch. Environ. Contam. Toxicol. 46: 399.

Stewart, I. R. K. and Westneat, D. F. 2010. Dietary calcium negatively affects the size of a status signal in juvenile male house sparrows (Passer domesticus). - The Auk 127: $549-557$.

Stewart, I. R. K. and Westneat, D. F. 2013. Dietary calcium, but not a glutathione inhibitor, affects bib size in juvenile male house sparrows. - The Condor 115: 921-930.

Symonds, M. R. E. and Moussalli, A. 2011. A brief guide to model selection, multimodel inference and model averaging in behavioural ecology using Akaike's information criterion. - Behav. Ecol. Sociobiol. 65: 13-21.

Valko, M. et al. 2005. Metals, toxicity and oxidative stress. - Curr. Med. Chem. 12: 11611208.

Vorobyev, M. et al. 1998. Tetrachromacy, oil droplets and bird plumage colours. - J. Comp. Physiol. [A] 183: 621-633.

Wolak, M. E. et al. 2012. Guidelines for estimating repeatability: Guidelines for estimating repeatability. - Methods Ecol. Evol. 3: 129-137. 
Wong and Svensson 2011. Carotenoid-based signals in behavioural ecology: a review. Behaviour 148: 131-189.

Xiao, M. et al. 2014. Nanostructural basis of rainbow-like iridescence in common bronzewing Phaps chalcoptera feathers. - Opt. Express 22: 14625.

Yin, H. et al. 2006. Iridescence in the neck feathers of domestic pigeons. - Phys. Rev. E 74: 051916.

Yoshioka, S. et al. 2007. Origin of two-color iridescence in rock dove's feather. - J. Phys. Soc. Jpn. 76: 013801.

Zahavi, A. and Zahavi, A. 1997. The handicap principle: a missing piece of Darwin's puzzle. Oxford University Press.

Zuur, A. F. et al. 2010. A protocol for data exploration to avoid common statistical problems: Data exploration. - Methods Ecol. Evol. 1: 3-14.

\section{ACKNOWLEDGMENTS}

All experiments were carried out in strict accordance with the recommendations of the "European Convention for the Protection of vertebrate Animals used for Experimental and Other Scientific Purposes" and were conducted under the authorizations of the "Ministère de l'éducation nationale, de l'enseignement supérieur et de la recherche" (authorization N_00093.02) and the "Direction Départementale des Services Vétérinaires de Seine etMarne" (authorization N_ 77-05). We thank the "Mairie de Paris" (Thomas Charachon) for allowing the capture of birds and the Centre de Recherche en Ecologie Expérimentale et Prédictive (CEREEP) which provided logistic support for the field work of this study. We are very thankful to T. Gayet, S. Pollet, S. Hasnaoui, F. Lorente, R. Guttières, S. Perret and B. Decencière for their help all along field work and to $C$. Biard for her help in 
spectrophotometric analysis. AP and SL were supported by a research grant from the "Agence Nationale de la Recherche" (No. ANR-13-PDOC-0002 to S.L.). We have no conflict of interest to disclose. 


\section{Table legends}

Table 1. Model-averaged estimates of in the best subset models $(\triangle \mathrm{AICc}<2)$ explaining iridescent colour in feral pigeons after lead and/or zinc supplementation (a) and at their capture in the wild (b).

Table 2. Model-averaged estimates of in the best subset models $(\triangle \mathrm{AICc}<2)$ explaining melanic colour (a) and feather melanic surface (b) in feral pigeons after lead and/or zinc supplementation. 
Table 1a

Iridescent feathers (metal supplementation)

\begin{tabular}{clll}
\multicolumn{2}{l}{ Iridescent feathers (metal supplementation) } & & \\
\hline & $\begin{array}{l}\text { Estimate } \pm \\
\text { adjusted SE }\end{array}$ & $\begin{array}{l}\text { Confidence } \\
\text { interval }\end{array}$ & $\begin{array}{l}\text { Relative } \\
\text { importance }\end{array}$ \\
\hline $\mathbf{Q}_{1}$ quantum catch & $0.162 \pm 0.002$ & $0.157,0.166$ & \\
\hline Intercept & $-0.006 \pm 0.003$ & $-0.012,0.0004$ & 0.80 \\
Feather colour type & $-0.00005 \pm 0.007$ & $-0.014,0.014$ & 0.56 \\
Sex & $0.0005 \pm 0.002$ & $-0.003,0.003$ & 0.27 \\
Morph & $0.002 \pm 0.003$ & $-0.003,0.008$ & 0.23 \\
Zinc exposure & $0.006 \pm 0.003$ & $-0.0002,0.011$ & 0.19 \\
Morph:Sex & & &
\end{tabular}

\section{$\mathbf{Q}_{2}$ quantum catch}

$\begin{array}{llll}\text { Intercept } & 0.256 \pm 0.003 & 0.249,0.262 & \\ \text { Feather colour type } & \mathbf{0 . 0 3 0} \pm \mathbf{0 . 0 0 8} & \mathbf{0 . 0 1 5 , 0 . 0 4 5} & \mathbf{1} \\ \text { Sex } & 0.011 \pm 0.007 & -0.002,0.024 & 0.58 \\ \text { Zinc exposure } & 0.009 \pm 0.007 & -0.004,0.022 & 0.45\end{array}$

$\underline{Q_{3} \text { quantum catch }}$

$\begin{array}{llll}\text { Intercept } & 0.360 \pm 0.005 & 0.346,0.373 & \\ \text { Feather colour type } & -\mathbf{0 . 0 4 5} \pm \mathbf{0 . 0 1 1} & -0.067,-\mathbf{0 . 0 2 4} & \mathbf{1} \\ \text { Sex } & -0.010 \pm 0.010 & -0.029,0.009 & 0.29 \\ \text { Zinc exposure } & -0.006 \pm 0.010 & -0.025,0.013 & 0.20\end{array}$

$\underline{\mathbf{Q}_{4} \text { quantum catch }}$

$\begin{array}{llll}\text { Intercept } & 0.225 \pm 0.0077 & 0.212,0.238 & \\ \text { Feather colour type } & \mathbf{0 . 0 2 2} \pm \mathbf{0 . 0 0 8} & \mathbf{0 . 0 0 6 , 0 . 0 3 8} & \mathbf{1} \\ \text { Morph } & -0.005 \pm 0.004 & -0.013,0.003 & 0.24 \\ \text { Sex } & -0.005 \pm 0.007 & -0.019,0.009 & 0.14 \\ \text { Zinc exposure } & -0.005 \pm 0.007 & -0.019,0.009 & 0.14 \\ \text { Lead exposure } & 0.004 \pm 0.007 & -0.010,0.018 & 0.13\end{array}$

Brightness

$\begin{array}{llll}\text { Intercept } & 0.263 \pm 0.019 & 0.226,0.299 & \\ \text { Lead exposure } & -0.033 \pm 0.016 & -0.065,-0.002 & 1 \\ \text { Morph } & -0.012 \pm 0.009 & -0.029,0.005 & 0.46\end{array}$


Table 1b

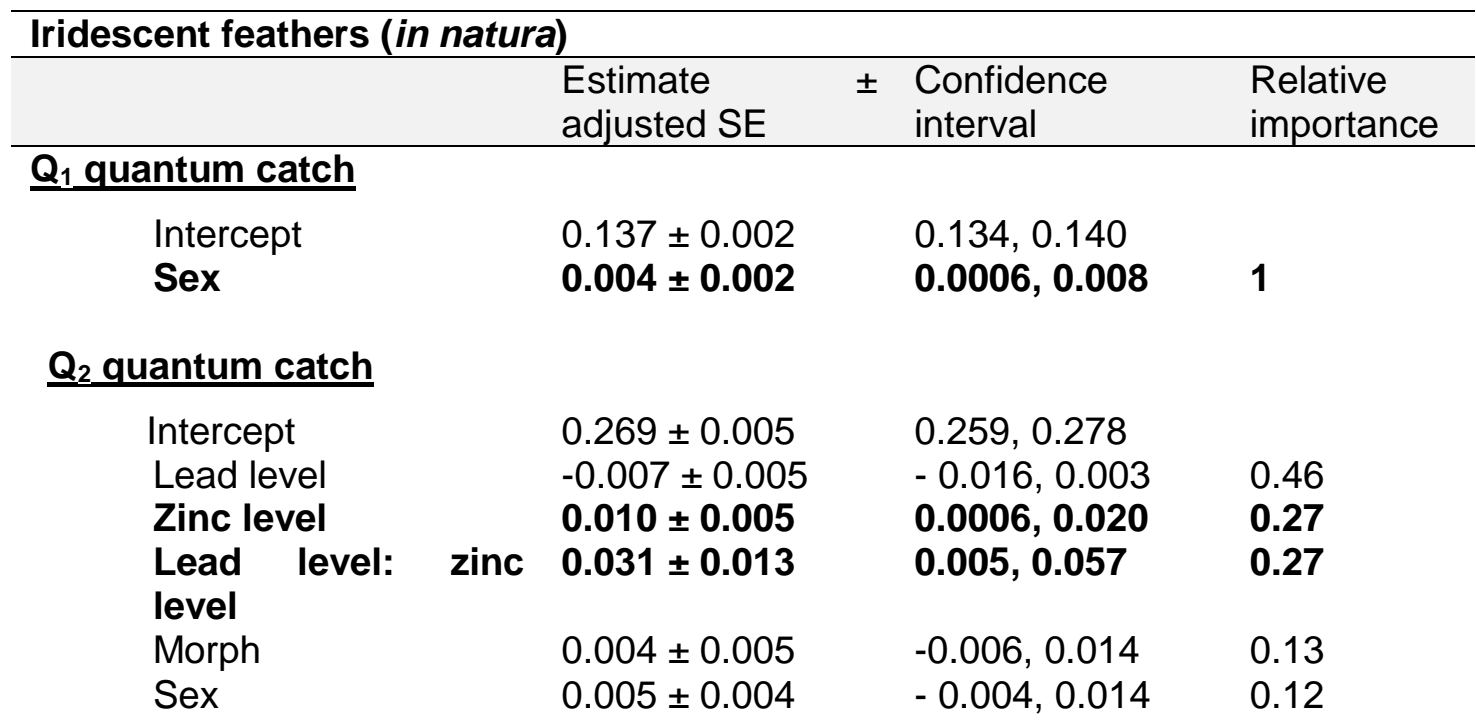

$\underline{Q_{3} \text { quantum catch }}$

$\begin{array}{lll}\text { Intercept } & 0.322 \pm 0.008 & 0.306,0.338\end{array}$

\section{$\underline{Q_{4} \text { quantum catch }}$}

$\begin{array}{llll}\text { Intercept } & 0.271 \pm 0.007 & 0.257,0.284 & \\ \text { Sex } & -\mathbf{0 . 0 1 1} \pm \mathbf{0 . 0 0 5} & \mathbf{- 0 . 0 2 1 , - 0 . 0 0 0} & \mathbf{0 . 6 0} \\ \text { Lead level } & 0.010 \pm 0.006 & -0.001,0.022 & 0.22 \\ \text { Zinc level } & -0.005 \pm 0.005 & -0.015,0.005 & 0.16\end{array}$

\section{Brightness}

Intercept

Lead levels
$0.710 \pm 0.144 \quad 0.039,0.605$

$-0.045 \pm 0.014 \quad-0.072,-0.018$

1 
Table 2a

\begin{tabular}{|c|c|c|c|}
\hline \multicolumn{4}{|l|}{ Melanic feathers (metal supplementation) } \\
\hline & $\begin{array}{l}\text { Estimate } \pm \\
\text { adjusted SE }\end{array}$ & $\begin{array}{l}\text { Confidence } \\
\text { interval }\end{array}$ & $\begin{array}{l}\text { Relative } \\
\text { importance }\end{array}$ \\
\hline \multicolumn{4}{|l|}{$\underline{Q}_{1}$ quantum catch } \\
\hline Intercept & $0.143 \pm 0.002$ & $0.139,0.147$ & \\
\hline Zinc exposure & $0.003 \pm 0.001$ & $0.0003,0.006$ & 1 \\
\hline Sex & $0.003 \pm 0.001$ & $-0.0004,0.006$ & 0.76 \\
\hline Morph & $0.001 \pm 0.0008$ & $-0.0002,0.003$ & 0.75 \\
\hline Sex: Zinc exposure & $0.003 \pm 0.003$ & $-0.003,0.008$ & 0.16 \\
\hline \multicolumn{4}{|l|}{$Q_{2}$ quantum catch } \\
\hline Intercept & $0.260 \pm 0.002$ & $0.256,0.263$ & \\
\hline Sex & $0.003 \pm 0.002$ & $-0.0004,0.007$ & 0.70 \\
\hline Morph & $0.001 \pm 0.001$ & $-0.0008,0.003$ & 0.31 \\
\hline Zinc exposure & $0.001 \pm 0.002$ & $-0.002,0.005$ & 0.12 \\
\hline Lead exposure & $-0.001 \pm 0.002$ & $-0.005,0.003$ & 0.11 \\
\hline \multicolumn{4}{|l|}{$\underline{Q}_{3}$ quantum catch } \\
\hline Intercept & $0.284 \pm 0.0005$ & $0.283,0.285$ & \\
\hline Lead exposure & $-0.0004 \pm 0.0006$ & $-0.002,0.0009$ & 0.30 \\
\hline Zinc exposure & $-0.0003 \pm 0.0006$ & $-0.002,0.0009$ & 0.29 \\
\hline Sex & $0.002 \pm 0.002$ & $-0.002,0.006$ & 0.28 \\
\hline Lead exposure: Zinc exposure & $0.003 \pm 0.001$ & $0.0002,0.005$ & 0.17 \\
\hline Morph & $0.00002 \pm 0.0003$ & $-0.0006,0.0007$ & 0.17 \\
\hline Morph: Sex & $-0.001 \pm 0.0007$ & $-0.003,-0.0002$ & 0.17 \\
\hline \multicolumn{4}{|l|}{$\mathrm{Q}_{4}$ quantum catch } \\
\hline Intercept & $0.313 \pm 0.004$ & $0.305,0.032$ & \\
\hline Sex & $-0.006 \pm 0.003$ & $-0.012,0.00005$ & 0.89 \\
\hline Morph & $-0.002 \pm 0.002$ & $-0.006,0.001$ & 0.51 \\
\hline Zinc exposure & $-0.004 \pm 0.003$ & $-0.010,0.002$ & 0.39 \\
\hline \multicolumn{4}{|l|}{ Brightness } \\
\hline Intercept & $0.115 \pm 0.003$ & $-0.109,0.121$ & \\
\hline Zinc exposure & $-0.010 \pm 0.006$ & $-0.023,0.002$ & 0.68 \\
\hline Lead exposure & $-0.010 \pm 0.006$ & $-0.023,0.002$ & 0.67 \\
\hline Zinc exposure & & & \\
\hline Lead exposure: Zinc exposure & $0.016 \pm 0.013$ & $-0.010,0.041$ & 0.17 \\
\hline Sex & $0.004 \pm 0.006$ & $-0.009,0.016$ & 0.09 \\
\hline
\end{tabular}


Table 2b

Feather melanic surface (metal supplementation)

Estimate

Confidence

Relative

\pm adjusted SE

interval

importance

Intercept

Sex

Morph

Zinc exposure

Sex : Zinc exposure

Sex: Moph
$0.317 \pm 0.009$

$0.005 \pm 0.016$

$0.077 \pm 0.018$

$-0.035 \pm 0.018$

$-0.037 \pm 0.042$

$0.043 \pm 0.044$
$0.030,0.335$

$-0.028,-0.041 \quad 0.77$

$0.041,0.113 \quad 1$

$-0.070,-0.00031$

$-0.134,0.003 \quad 0.56$

$0.0008,0.140 \quad 0.61$ 


\section{Figure legends}

Figure 1. Mean reflectance spectra \pm confidence intervals (a) and mean brightness \pm confidence intervals of iridescent feathers of pigeons according to lead treatment in the experimental and the correlative approach, respectively. The bold and the dotted lines correspond to the regression line and to the $95 \%$ confidence interval of the model, respectively. In the experimental approach (a), birds not exposed to lead (in blue) correspond to controls and birds exposed to zinc only, while birds exposed to lead (in red) correspond to birds exposed to lead only and birds exposed to both lead and zinc. In the correlative approach (b), the results of the model were similar when removing the two outliers (estimate \pm adjusted SE and confidence interval of lead levels: $-0.04 \pm 0.01$ and $-0.069,-0.015$, relative importance: 1$)$.

Figure 2. Reflectance in blue-wavelengths of iridescent feathers according to lead levels in feathers in pigeons with high and low zinc levels in the correlative approach. Although zinc level was analyzed as a continuous variable, for illustrative purpose, pigeons were split into two categories of zinc levels. We considered zinc levels $<150 \mathrm{mg} / \mathrm{g}$ as low ( $\mathrm{n}=14$ pigeons) and zinc levels $>150 \mathrm{mg} / \mathrm{g}$ as high ( $\mathrm{n}=14$ pigeons). The bold and the dotted lines correspond to the regression line and to the $95 \%$ confidence interval of the model, respectively.

Figure 3. Reflectance in violet (a) and green-wavelengths (b) of melanic feathers of pigeons according to metal supplementation (i.e. lead and/or zinc exposure). Letters $a$ and $b$ indicate that the mean is significantly different from that of the other treatments (Student test, see results). 
Figure 1a

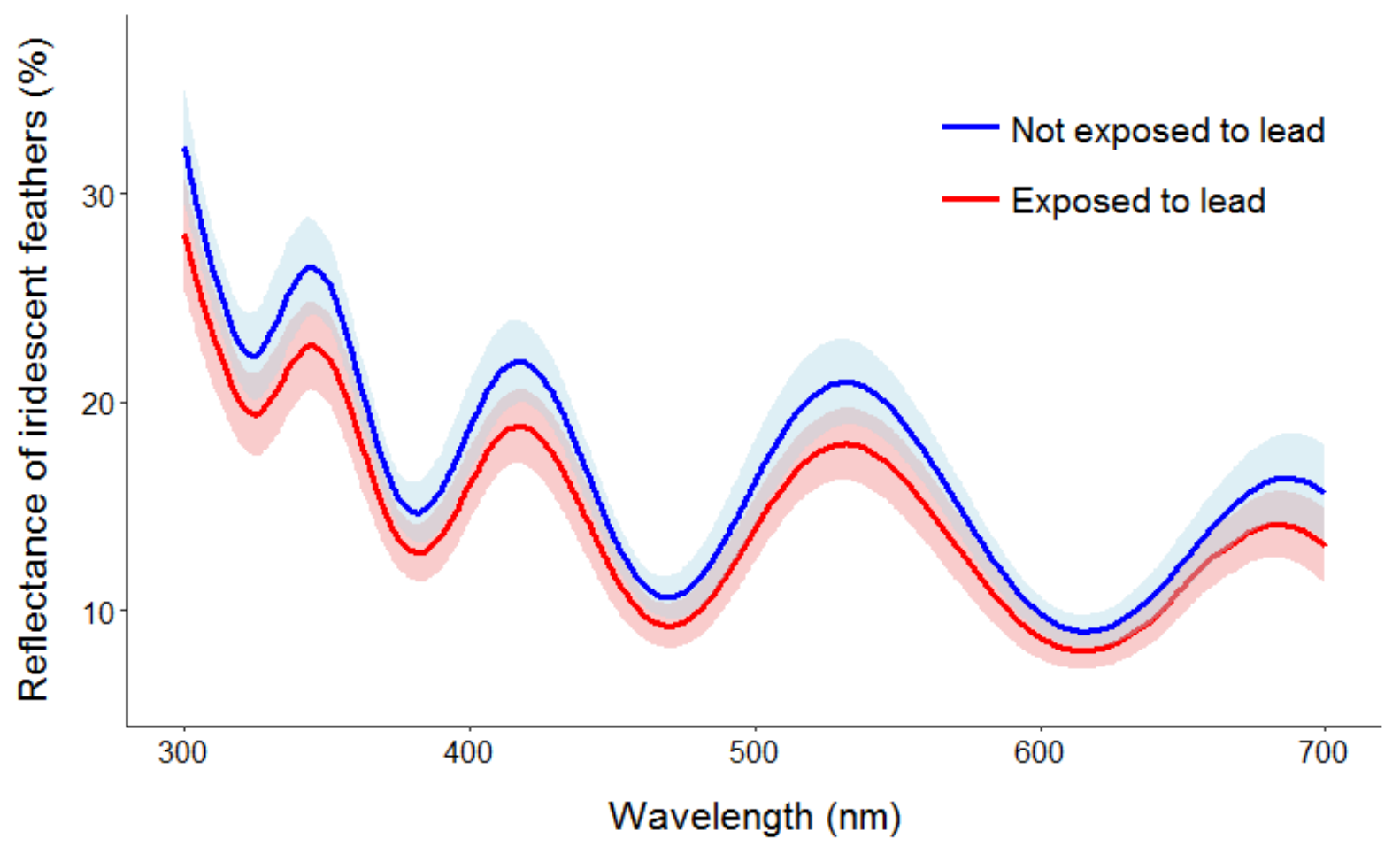

Figure 1b

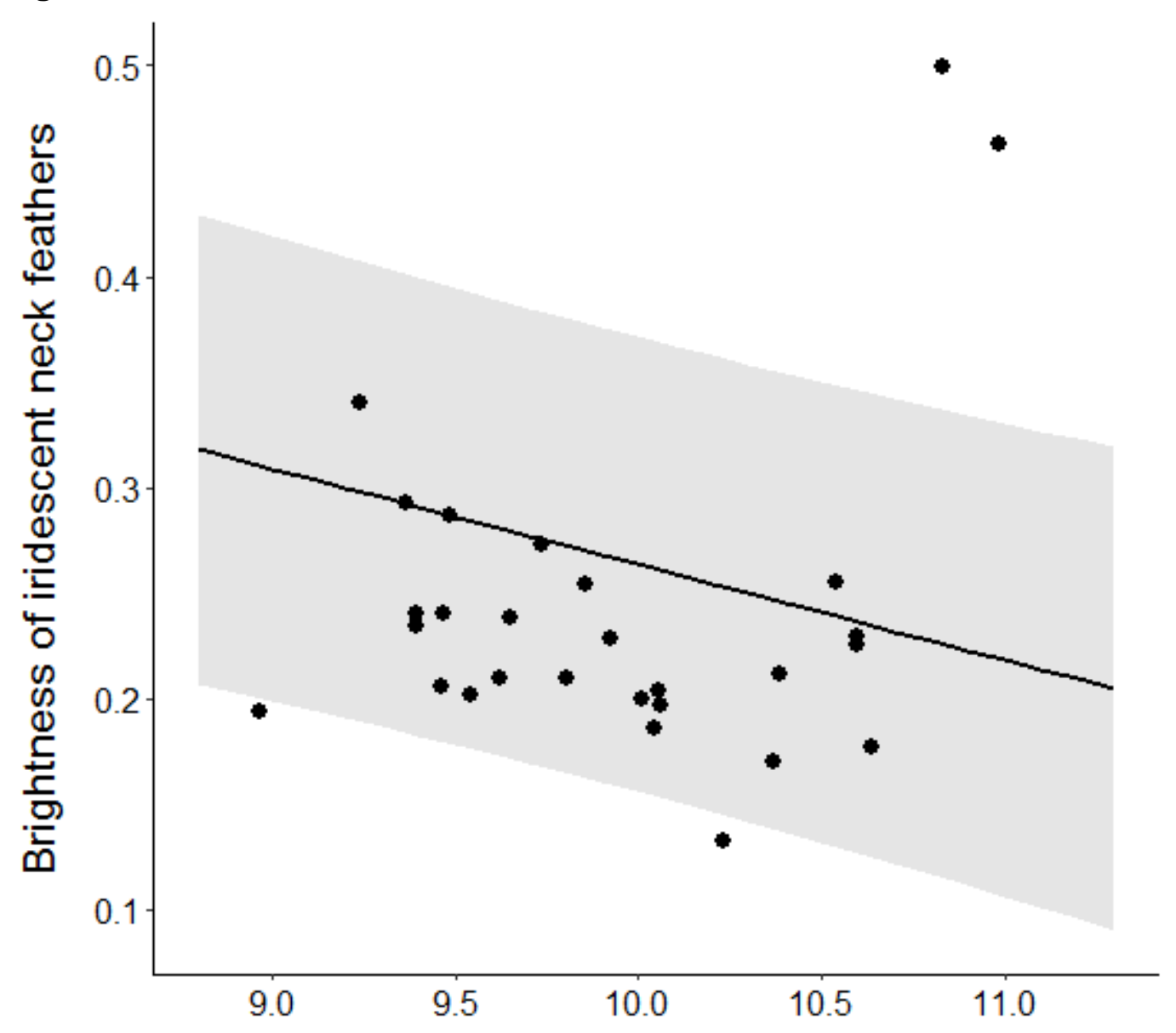

Lead levels in feathers (in $\mu \mathrm{g} / \mathrm{g}$; log-transformed) 
Figure 2

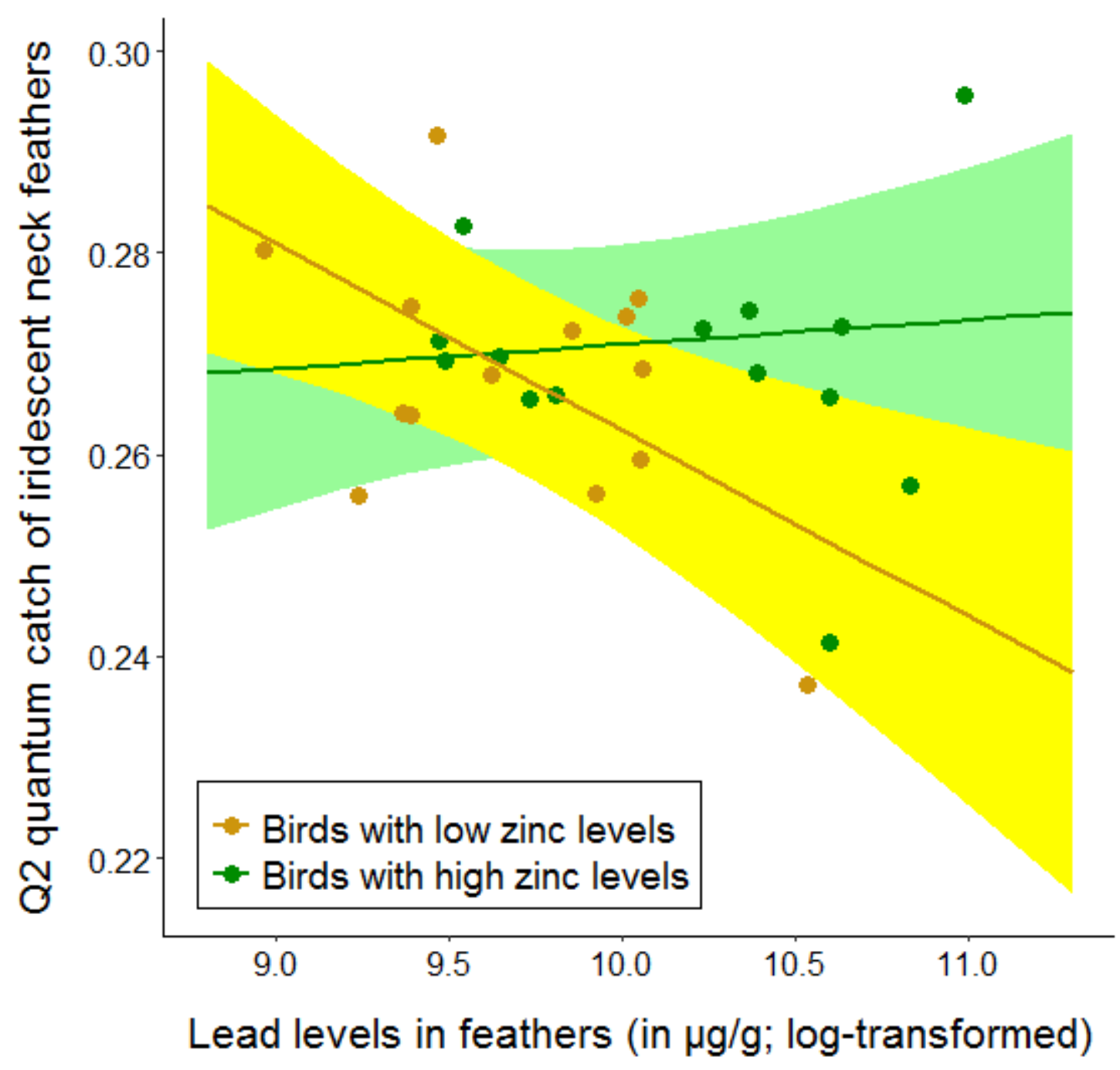


Figure $3 a$

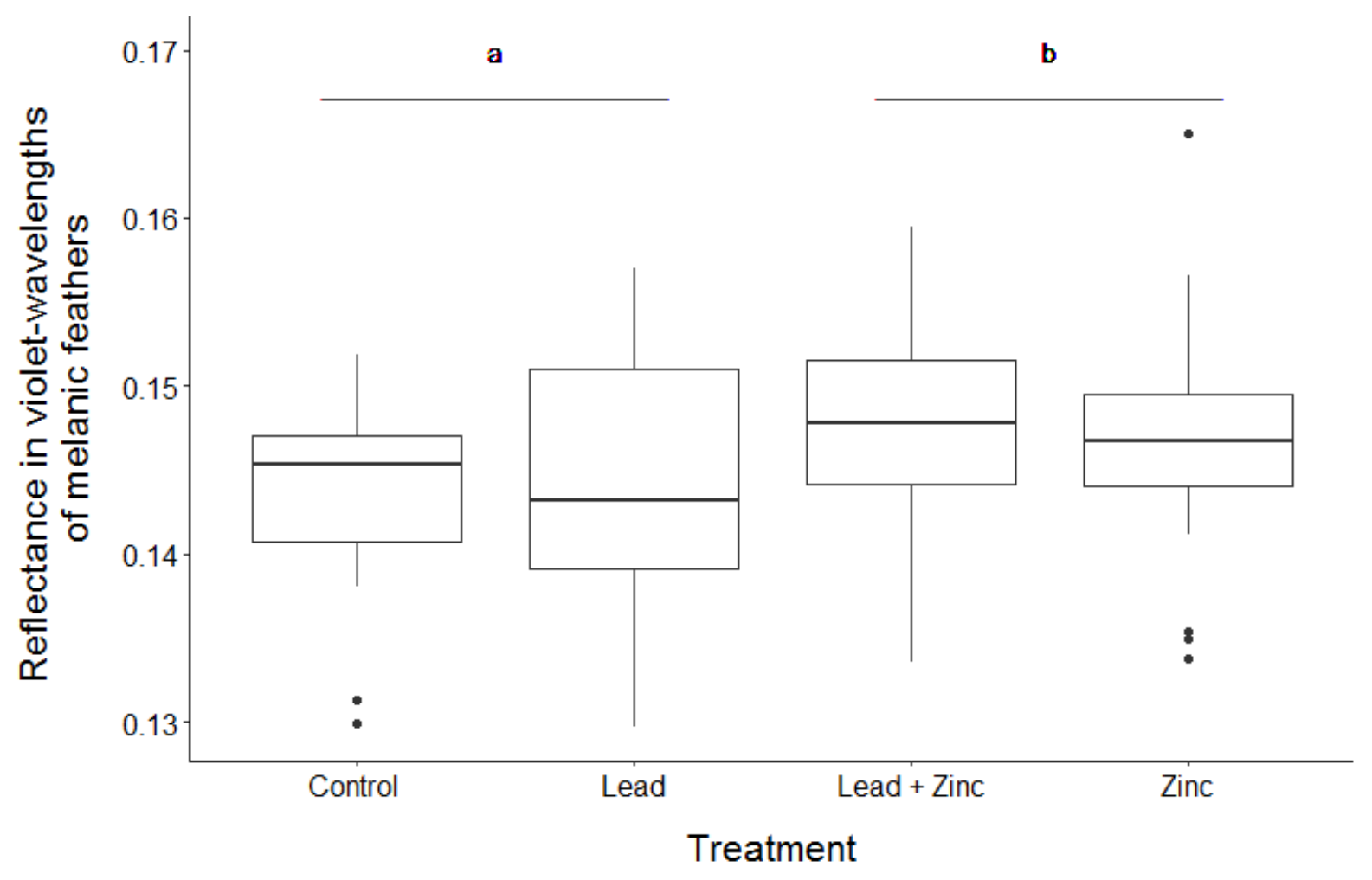

Figure 3b

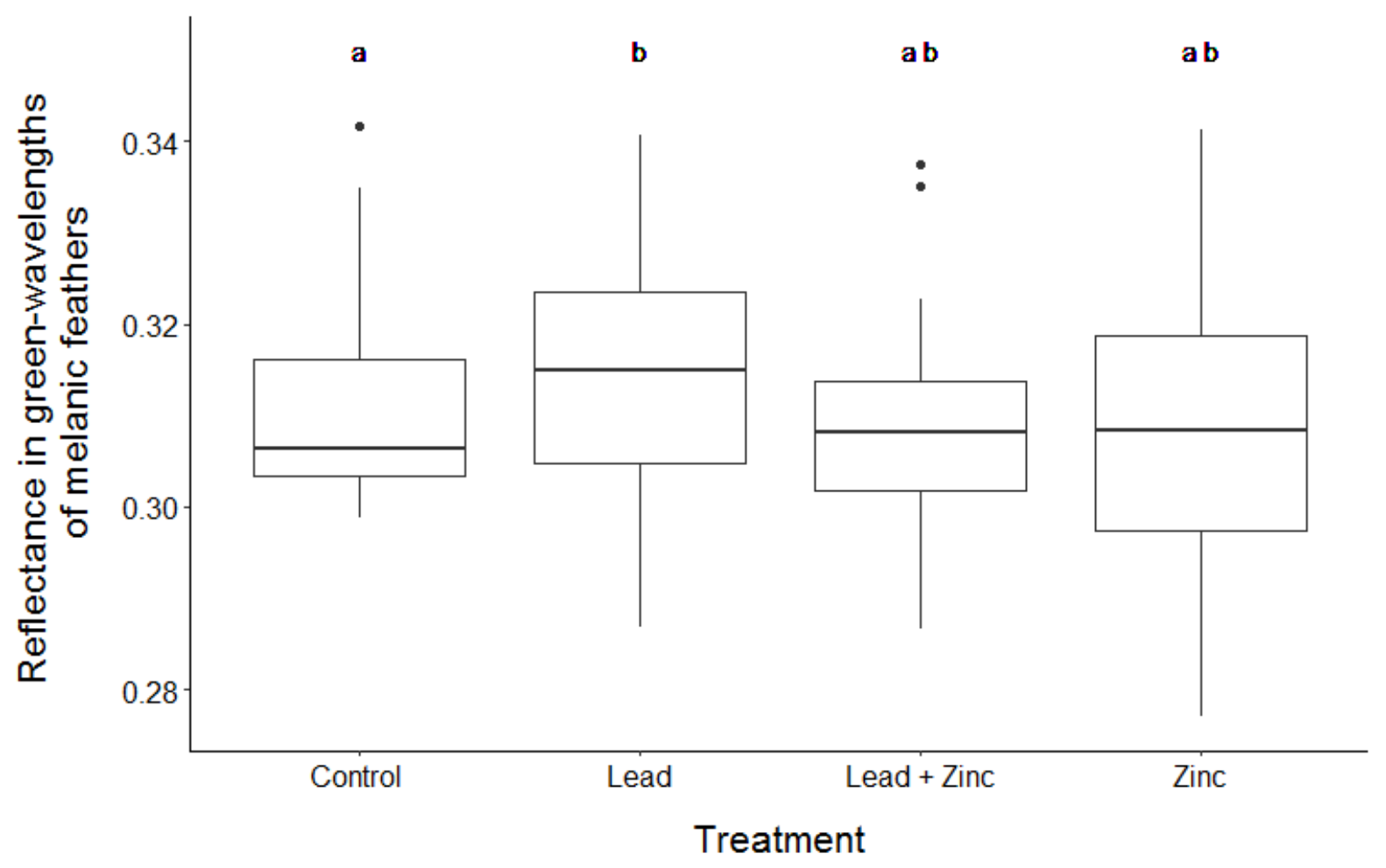




\section{SUPPLEMENTARY MATERIAL}

Appendix 1- Table A1. Mean and confidence interval of brightness and reflectance in violet $\left(Q_{1}\right)$, blue $\left(Q_{2}\right)$, green $\left(Q_{3}\right)$ and yellow-wavelengths $\left(Q_{4}\right)$ of iridescent (a) and melanic feathers (b) in pheomelanic pigeons. Pheomelanic pigeons have been exposed to three out of the four treatments: control, lead and zinc (i.e. none of the pheomelanic pigeons were exposed to both lead and zinc).

\begin{tabular}{lccccc} 
a) & Brightness & $\begin{array}{c}\text { Violet- } \\
\text { wavelengths }\end{array}$ & $\begin{array}{c}\text { Blue- } \\
\text { wavelengths }\end{array}$ & $\begin{array}{c}\text { Green- } \\
\text { wavelengths }\end{array}$ & $\begin{array}{c}\text { Yellow- } \\
\text { wavelengths }\end{array}$ \\
\hline \multirow{2}{*}{ Control } & 0.429 & 0.115 & 0.242 & 0.286 & 0.357 \\
& $0.198-0.660$ & $0.097-0.133$ & $0.183-0.301$ & $0.239-0.336$ & $0.305-0.409$ \\
\hline \multirow{2}{*}{ Lead } & 0.312 & 0.114 & 0.229 & 0.298 & 0.359 \\
& $0.257-0.367$ & $0.107-0.122$ & $0.193-0.264$ & $0.255-0.341$ & $0.347-0.371$ \\
\hline \multirow{2}{*}{ Zinc } & 0.387 & 0.109 & 0.224 & 0.304 & 0.387 \\
& $0.362-0.412$ & $0.096-0.122$ & $0.200-0.248$ & $0.288-0.320$ & $0.362-0.412$ \\
\hline
\end{tabular}

\begin{tabular}{|c|c|c|c|c|c|}
\hline b) & Brightness & $\begin{array}{c}\text { Violet- } \\
\text { wavelengths }\end{array}$ & $\begin{array}{c}\text { Blue- } \\
\text { wavelengths }\end{array}$ & $\begin{array}{c}\text { Green- } \\
\text { wavelengths }\end{array}$ & $\begin{array}{c}\text { Yellow- } \\
\text { wavelengths }\end{array}$ \\
\hline Control & $\begin{array}{c}0.577 \\
0.332-0.821\end{array}$ & $\begin{array}{c}0.123 \\
0.111-0.136\end{array}$ & $\begin{array}{c}0.249 \\
0.231-0.267\end{array}$ & $\begin{array}{c}0.289 \\
0.287-0.291\end{array}$ & $\begin{array}{c}0.338 \\
0.308-0.369\end{array}$ \\
\hline Lead & $\begin{array}{c}0.714 \\
0.544-0.884\end{array}$ & $\begin{array}{c}0.115 \\
0.104-0.126\end{array}$ & $\begin{array}{c}0.239 \\
0.220-0.258\end{array}$ & $\begin{array}{c}0.291 \\
0.288-0.294\end{array}$ & $\begin{array}{c}0.355 \\
0.324-0.387\end{array}$ \\
\hline Zinc & $\begin{array}{c}0.861 \\
0.713-1.01\end{array}$ & $\begin{array}{c}0.129 \\
0.117-0.140\end{array}$ & $\begin{array}{c}0.263 \\
0.250-0.276\end{array}$ & $\begin{array}{c}0.292 \\
0.289-0.295\end{array}$ & $\begin{array}{c}0.316 \\
0.293-0338\end{array}$ \\
\hline
\end{tabular}


Appendix 2- Picture A2. Variation in eumelanin-based plumage colouration in the feral pigeon. Eumelanin level is divided in 5 colour morphs coded from 0 (full white) to 5 (full black).

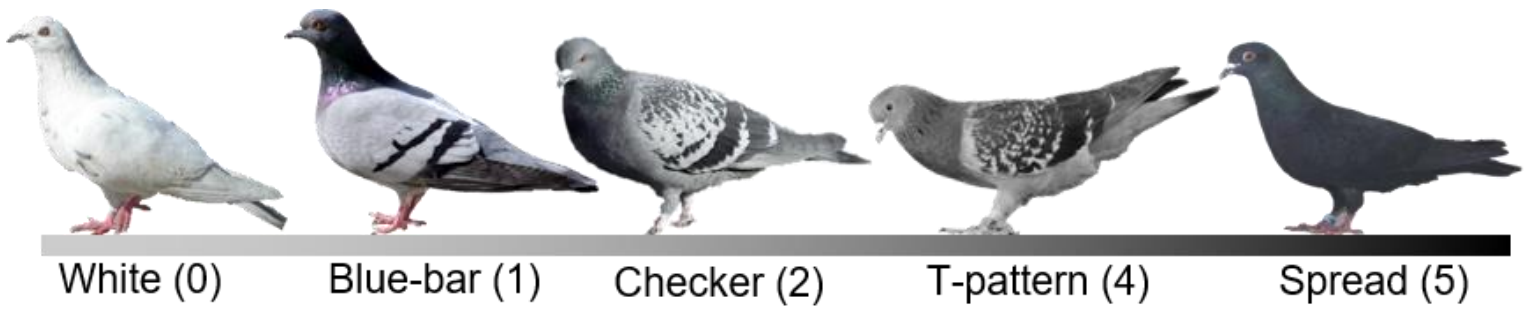

